\title{
Cancers of unknown primary origin: current perspectives and future therapeutic strategies
}

\author{
Giulia Maria Stella ${ }^{1,2^{*}}$, Rebecca Senetta ${ }^{3}$, Adele Cassenti ${ }^{3}$, Margherita Ronco ${ }^{3}$ and Paola Cassoni ${ }^{3}$
}

\begin{abstract}
It is widely accepted that systemic neoplastic spread is a late event in tumour progression. However, sometimes, rapidly invasive cancers are diagnosed because of appearance of metastatic lesions in absence of a clearly detectable primary mass. This kind of disease is referred to as cancer of unknown primary (CUP) origin and accounts for 3-5\% of all cancer diagnosis. There is poor consensus on the extent of diagnostic and pathologic evaluations required for these enigmatic cases which still lack effective treatment. Although technology to predict the primary tumour site of origin is improving rapidly, the key issue is concerning the biology which drives early occult metastatic spreading. This review provides the state of the art about clinical and therapeutic management of this malignant syndrome; main interest is addressed to the most recent improvements in CUP molecular biology and pathology, which will lead to successful tailored therapeutic options.
\end{abstract}

Keywords: Cancer, Metastases, Invasive growth, Mutations

\section{Introduction}

Cancer of unknown primary (CUP) origin defines metastatic tumour detected when the site of primary origin cannot be identified based on clinical history, complete physical examination, routine laboratory tests, imaging and radio-metabolic techniques and careful review of histological specimens. Although this malignant syndrome accounts for $3-5 \%$ of all cancer diagnosis, the majority of patients still lacks effective therapeutic regimens [1] CUP clinical presentation is extremely heterogeneous: about $15-20 \%$ of CUP patients can be assigned to favourable subsets whereas the others share a very aggressive potential and unpredictable pattern of metastatic spread. The largest group of these tumours is refractory to standard chemotherapy and the median survival of CUP patients is very low.

There is poor consensus on the extent of diagnostic evaluations in front of metastatic cancers without a primary mass. At the present immunohistochemistry (IHC) is often the only standard method by which a putative primary origin can be postulated. Nevertheless, recent improvements in molecular diagnostics will allow a

\footnotetext{
* Correspondence: giulia.stella@ircc.it

'Department of Oncological Sciences, Institute for Cancer Research and Treatment (IRCC), 10060 Candiolo (Turin), Italy

Full list of author information is available at the end of the article
}

most appropriate pathological classification of early metastases. However the most relevant approach to CUP is related to the understanding of the biology which drives precocious metastatic spreading.

This review summarizes the current knowledge on pathological features, diagnostic tools and biological behaviour of CUPs, mainly focusing on the next future therapeutic implications.

\section{CUP: definition, epidemiology and clinical approach}

Almost one third of advanced tumours presents with metastases at time of diagnosis. In the majority of cases the organ site of primary lesion becomes shortly evident after clinical, pathological and radio-metabolic evaluations. The other cases can be roughly defined as metastases of unknown primary origin. Indeed this definition includes two groups of tumours: 1) the cases in which the primary site might be postulated at least by their $\mathrm{ICH}$ profile; 2) the metastatic lesions which remain really 'orphan' even after an exhaustive IHC screening. Although the separation into two groups based on the IHC profile could be somehow artificial, it may be important for patient management and the choice of initial therapeutic regimen.

\section{Biomed Central}

(c) 2012 Stella et al; licensee BioMed Central Ltd. This is an Open Access article distributed under the terms of the Creative Commons Attribution License (http://creativecommons.org/licenses/by/2.0), which permits unrestricted use, distribution, and reproduction in any medium, provided the original work is properly cited. 
It is generally reported that the incidence of CUPs is about $3-5 \%$ of all cancer diagnosis [2]. The annual ageadjusted incidence per 100,000 population in USA is 712 cases; in Australia 18-19 cases and in the Netherlands 5.3-6.7 cases [3]; however it must be kept in consideration that the incidence might be higher since some CUPs patients are classified for pragmatic clinical reasons as 'known primary' even if their diagnosis is uncertain. The median age at diagnosis is reported to be 60 years and the occurrence is slightly higher in males. In some instances, although the metastatic pattern is often unpredictable, the site of primary origin can be found during lifetime or autopsy: it is generally a small nodule often localized in the lungs or in the bilio-pancreatic tract [4].

In the early 1970s some researchers argued that diagnosis of cancer of unknown primary origin could only be made if the primary tumour was not found at autopsy [5]. At the present, as suggested by International Guidelines (http://www.nccn.org,http://www. esmo.org), all the patients who present with a metastatic cancer suspected to be of unknown primary should have an accurate physical examination, complete laboratory tests and a whole body imaging study (Computed Tomography - CT - scan and Positron Emission Tomography - PET). Besides, female patients have to undergo mammography and vaginal ultrasound (US) scan, whereas prostate US scan is required in males. Various endoscopic procedures (laryngoscopy, bronchoscopy, gastroscopy, colonoscopy or cystoscopy) should be ordered in selective cases, based on several clinical factors such as patients' relevant symptoms and/or signs, physical examination findings, sites of metastases, occult blood in the stool, laboratory findings as well as any other factor which would prompt endoscopies. More than $50 \%$ of CUP patients present with multiple sites of involvement while the rest have a single site, most commonly liver, bone, lung or lymph nodes [6].

CUP patients are classified into subgroups and specific risk categories according to the organs involved (disease stage) and histology in order to optimize patient management [7]. A minority (15-20\%) of patients belongs to the subset at more favourable prognosis: these patients harbour the most differentiated and chemosensitive tumors and have the longest survival rates. Unfortunately the majority of cases do not belong to any specific category. These cases have the worst prognosis, displaying a substantial resistance to therapy. Unfavourable predictor factors are related to diagnosis of: adenocarcinoma metastatic to liver, non-papillary malignant ascites, multiple cerebral metastases, multiple lung/ pleural metastases, systemic bone disease. Better prognosis is, on the other hand, related to: poorly differentiated carcinoma with midline-distribution, papillary adenocarcinoma of peritoneal cavity (in women), adenocarcinoma involving only axillary lymph nodes (in women), squamous cell carcinoma involving cervical lymph nodes, isolated malignant adenopathy, poorly differentiated neuro-endocrine carcinoma, single small and potentially resectable tumour $[2,6]$. Notably, it seems that CUP survivors have a higher risk of developing many subsequent cancers [8]. The overall prognosis of CUP patients is generally very poor with a median survival of 4-12 months, with about $50 \%$ of patients alive at 1 year and about $10 \%$ at 5 years from diagnosis [9]. Therapy is currently designed on the bases of clinical-pathological investigations and according to disease staging and risk assessment; at the present the optimal chemotherapeutic regimens remains to be clarified and the most commonly used regimens contain platinum [1].

\section{Pathologic presentation and analysis}

Cancer can arise in any tissue of the body. In the vast majority of cases, the first step in cancer onset is the growth of a primary lesion; only later a metastatic clone acquires the biological properties required to detach from the mass, invade lymphatic or blood vessels and eventually colonize distant organs. Nevertheless some exceptions from this behaviour might be underlined. Sometimes tumours arise as multiple primary lesions. They could be: i) synchronous tumours and can display different histology or share the same histology but be anatomically separated; ii) metachronous nodules with the same histology, but temporarily separated each other. Multiple nodules can also identify satellite nodules of a primary lesion if they share the histology of the primary tumor and are spatially separated within the same organ. Finally multiple neoplastic nodules might be metastases, which have spread from a primary tumor and grown with a spatial and temporal $(<2$ years $)$ interval from it. From the anatomic perspective, metastasis can leave the primary site through a cavity (e.g. from lungs to the pleural cavity or from colon to peritoneum); by lymphatic spreading or through blood vessels. Cancer cells can even migrate across the endothelium, the basement membrane or along neurons [10-13]. In general metastatic cells maintain the histologic features of the tissue from which they derive, even in case of upfront metastatic cancers. However, in a number of cases, cancer cells appear as multiple nodules which do not display morphology and properties referable to the tissue/organ in which they are arising or cannot be related to any suspected distant primary site. The latter identify cancers of unknown primary (CUP) origin (Figure 1).

When CUP is suspected, the diagnostic algorithm followed by pathologists has to be-at the same time-strict and extensive. The vast majority of CUPs are 


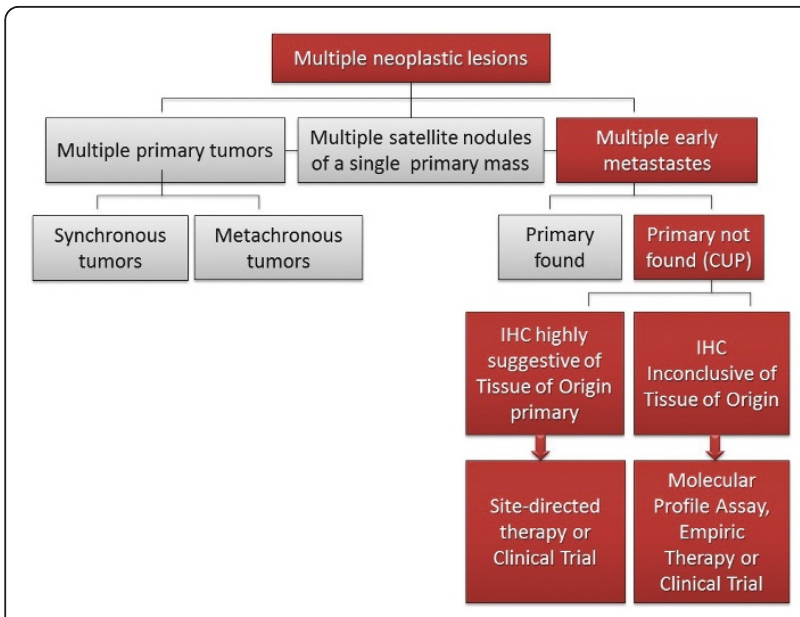

Figure 1 Tacking the primary: from multiple malignant nodules to CUPs.

represented by carcinomas; with respect to the cancer morphology, CUP can be classified as: i) well, moderately or poorly differentiated adenocarcinomas; ii) squamous cell carcinomas; iii) poorly differentiated carcinomas, iv) carcinomas with neuroendocrine differentiation; v) undifferentiated cancers. Adenocarcinomas of unknown primary are the most frequently diagnosed. In such settings, immunohistochemistry is the only standard test which could be the determining factor to suggest the primary origin of the lesion. Several immunohistochemical markers have been proposed to predict the site of the primary tumor. As recently suggested by Greco FA et al. [14] the screening panel might include citokeratins (CK-7; CK-20), TTF-1; breast/ovarian markers, HEPAR-1, renal cell, placental alkaline phosphatase/OCT-4, WT-1/PAX8, synaptophisin and chromogranin. IHC accurately predicts a (single) primary in $\sim 35 / 40 \%$ of early metastatic cancers [6]. It has been demonstrated that panels of markers are superior to single biomarkers in identifying the primary site, at least in adenocarcinomas. Dennis JL and coll. [15] provided correct primary site identification in $88 \%$ of cases of metastatic adenocarcinoma applying an immunohistochemical diagnostic algorithm including 10 immunohistochemical markers. However it should be noted that these studies were done in patients with known metastatic cancers, rather than in patients with CUP. Thus, their findings, although important, may not be entirely analogous to patients with unknown primary cancer. Besides, the pathologic evaluation is in the vast majority of cases performed on formalin-fixed paraffinembedded (FFPE) small sized samples, mainly derived from bioptic procedures. Besides, the choice of IHC panel deeply influences subsequent diagnosis $[16,17]$. Moreover IHC lacks of specificity and sensitivity in staining some primary tumors, such as upper gastrointestinal cancers (gastro-esophageal and pancreatico-biliary tumor). As a consequence, in a number of cases the IHC markers profile may only suggest a differential diagnosis rather than indicate a conclusive single diagnosis.

In conclusion, the diagnostic procedure begins if necessary by determining the cell lineage (epithelial, melanocytic, lymphoid, mesenchymal, germinal cells) with the aid of appropriate markers; the IHC panel will be then determined coherently. Here we propose a hypothetical ideal IHC diagnostic algorithm for screening and issuing towards tumor primary, which may be used once the tumor has been confirmed to be a carcinoma (Figure 2). It should be remarked that, although complete and concise, realistically, this approach could not be recommended in all patients. The clinical circumstances, including the patient's gender, site of metastasis, histologic appearance of their tumor and the screening immunohistochemistry of CK-7, CK-20, TTF1 and CDX-2 might be considered as first step and subsequent staining needs to be individualized, based upon patient's clinical pathologic setting.

There are few reports focusing on the validation of the predictive value of the immunophenotype in CUPs. From this perspective, classical pathologic approach can be integrated by molecular biology and gene expression profiling studies. In 2008 Horling $\mathrm{H}$ and coll. [18] showed that the IHC prediction of primary was consistent with the molecular profiling in a series of adenocarcinoma of unknown primary.

In summary, in some cases IHC algorithms can allow the identification of a primary site with adequate accuracy but, at the present, there are not enough precise knowledge to definitely distinguish two different groups, those with and without IHC-solved primary. As a consequence, unless patients have a clinically defined and anatomically recognized primary site-discovered at the time of the workup or later in the course of their disease, have CUP. It means that-at the present-there is no enough precise knowledge to state that those cancers without a strong IHC single diagnosis are definitely different from the others. However, a precise and recognized immunohistochemical profile may lead to appropriate treatment in individual patient's settings. This approach has been clearly supported by Varadhachary GR and coll. [19] and more recently by Greco FA and Hainsworth JD [20]: in both cases, authors described a CUP featuring the CDX-2 and CK20 +, CK7 staining profile and they defined it as a 'colon cancer profile CUP (CCP-CUP)'. Importantly, it has been shown that this subset of patients better responds and seems to have a superior outcome when treated with site-specific therapy. 


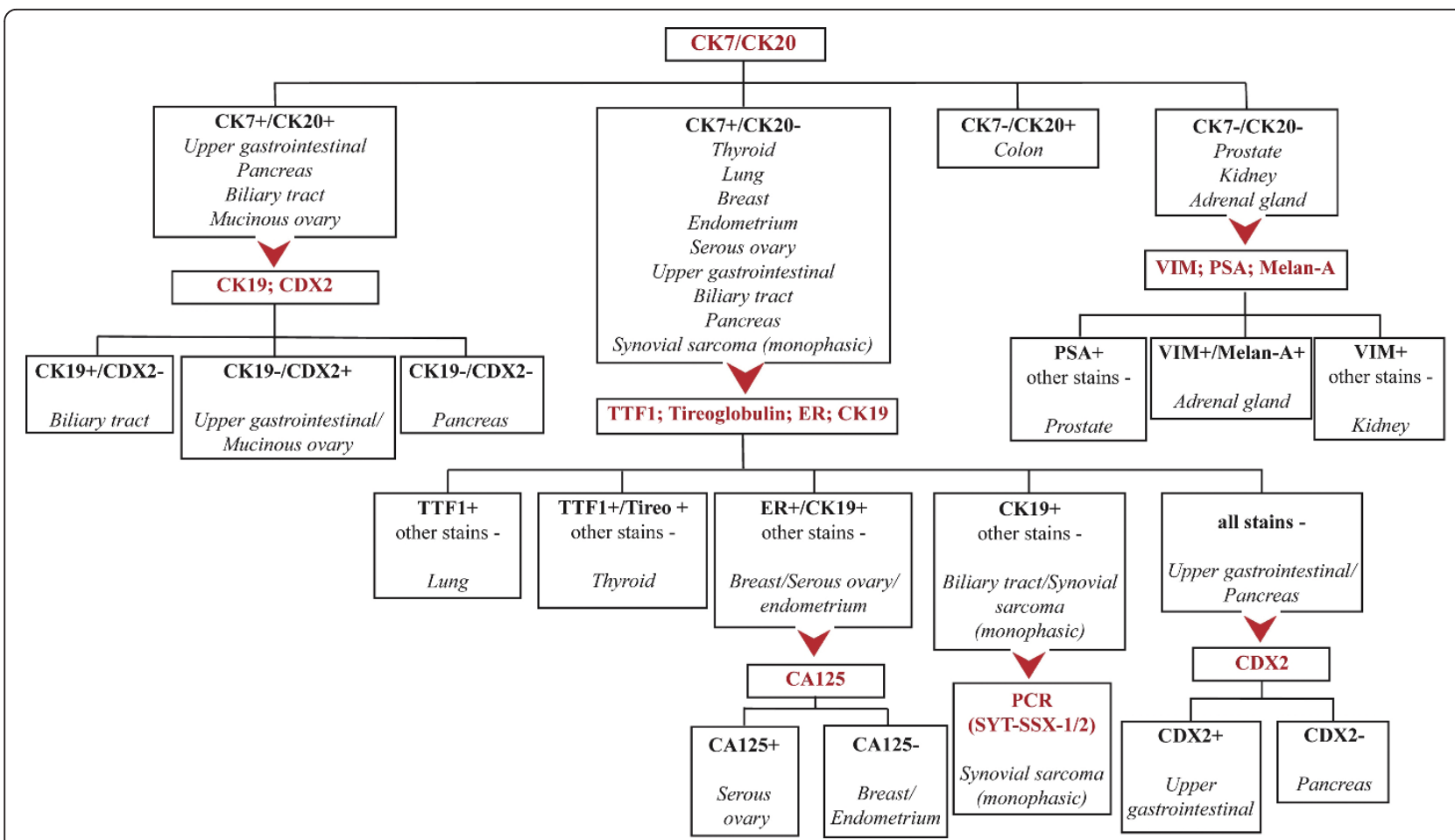

Figure 2 Diagnostic algorithm to characterize metastatic adenocarcinoma from unknown primary. (CK: cytokeratin; TTF1: thyroid transcription factor 1; ER: estrogen receptor; CA125: cancer antigen 125; tireo: tireoglobulin; VIM: vimentin; PSA: prostate specific antigen)

\section{The role and contribution of imaging}

Detection of the primary tumor may optimize treatment planning, which, in turn, may improve patient prognosis. This goal might be considered in front of a suspect of metastatic cancers of occult primary. Since the unknown primary mass can be located anywhere in the body, a cross-sectional whole-body imaging modality is the proper method to look for a primary site. Ultrasound is a fairly quick and easy procedure that doesn't use radiation, which is why it is often one of the first tests done if an internal mass is suspected; computed tomography (CT) and magnetic resonance (MRI) thus represent the imaging studies most used in clinical practice to dissect the whole body. The combination of 18 F-fluorodeoxyglucose (FDG) positron emission tomography (FDGPET) and CT has gained wide acceptance, especially if the primary tumor is unknown. It should be noted that small lesions or pathological changes in normal-sized tissues can be missed by CT and MRI; this is especially relevant in CUP setting in which the primary tumor is supposed to be a small lesion [21]. From this perspective, positron emission tomography using the radiotracer 18 F-fluoro-2-deoxyglucose, is the leading approach since it provides functional and metabolic information with an excellent lesion $v s$ background ratio. Notably, studies of unknown primary malignancies are among the most appropriate indications for PET, according to international nuclear medicine guidelines [22]. Integration of PET/CT scanner (equipped with a 16- to 64-section multidetector-row CT unit) is rapidly replacing the PET study alone and is at the present the preferred method of choice for the detection of primary tumors in patients with CUP. Notably, PET/CT imaging is known to have a good sensitivity and specificity, mainly in head and neck and lung cancers [23]. A true positive result is considered when the imaging-suggested putative primary is subsequently confirmed through biopsy. On the other hand, a false negative result is considered if the primary tumor is detected in a site that is negative on the imaging technique. A recent meta-analysis [24] showed that, overall, FDG-PET/CT is able to detect $37 \%$ of primary tumors in patients with CUP, with both sensitivity and specificity of $84 \%$. Although data as a whole are encouraging it should be noted that cohorts of CUP patients analyzed in each study are extremely mixed and heterogeneous (Table 1).

In conclusion the diagnostic challenge for $\mathrm{PET} / \mathrm{CT}$ is to minimize the false negative in tracking the primary tumor. FDG is a nonspecific radiotracer with can accumulate also in no-malignant areas of increased glycolysis, such as inflammatory areas. A number of radiotracers are under investigation including compounds that can mark hypoxia, angiogenesis and apoptosis in tumors. Advances in PET technology and the integration of PET/MRI as 
Table 1 Predictive values of PET in tracking the primary site in case of early metastatic cancers

\begin{tabular}{|c|c|c|c|c|}
\hline $\begin{array}{l}\text { Match PET/histology in identification of the } \\
\text { primary lesion }\end{array}$ & $\begin{array}{l}\text { Total examined } \\
\text { cases }\end{array}$ & $\begin{array}{l}\text { Predictive value of PET\% ( } n \text { of } \\
\text { patients) }\end{array}$ & $\begin{array}{l}\text { False positive cases\% (n of } \\
\text { patients) }\end{array}$ & Reference \\
\hline Failed & 1 & - & - & [25] \\
\hline 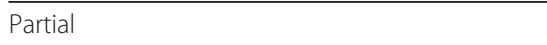 & 23 & $56,5(13)$ & - & {$[26]$} \\
\hline Partial & 39 & $27(6)$ & $2.5(1)$ & [27] \\
\hline Failed & 18 & - & - & [28] \\
\hline Partial & 20 & 11(55) & $5(1)$ & [29] \\
\hline Partial & 149 & 24.8 (37) & 8.7 (13) & [30] \\
\hline Failed & 20 & - & - & [31] \\
\hline Partial & 51 & $9.6(5)$ & - & [32] \\
\hline Partial & 77 & 36.4 (28) & $1.2(1)$ & [33] \\
\hline $\begin{array}{l}\text { Partial } \\
\text { nal }\end{array}$ & 24 & $37.5(9)$ & $12.5(3)$ & [34] \\
\hline Complete & 1 & 1 & - & [35] \\
\hline Partial & 59 & 59 (35) & - & [36] \\
\hline 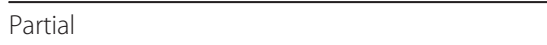 & 44 & $31.8(14)$ & $11.3(1)$ & [37] \\
\hline Partial & 47 & $14.8(7)$ & $27.6(13)$ & [38] \\
\hline Partial & 13 & $7(54)$ & - & [39] \\
\hline Partial & 43 & $55.8(24)$ & $2.3(1)$ & [40] \\
\hline Partial & 67 & $53.7(36)$ & 1. 49 (1) & [41] \\
\hline Partial & 430 & 31.4 (135) & $3.9(17)$ & [42] \\
\hline Partial & 60 & $30(18)$ & $21.6(13)$ & [43] \\
\hline Partial & 39 & $26(10)$ & - & [44] \\
\hline $\begin{array}{l}\text { Partial } \\
\end{array}$ & 15 & $20(4)$ & $6.6(1)$ & [45] \\
\hline $\begin{array}{l}\text { Partial } \\
\end{array}$ & 14 & $40(7)$ & $7.1(1)$ & [46] \\
\hline Partial & 38 & $53(20)$ & $2.6(1)$ & [47] \\
\hline
\end{tabular}

well as improvements of the hardware for data analysis are expected to improve the management of CUP patients.

\section{Molecular profiling for the identification of the primary tissue-of-origin}

Despite the large number of patients diagnosed with carcinoma of unknown primary site of origin, innovative and individualized approaches to managing these patients have lagged behind many other solid tumors. At the present great efforts are directed to take advantages from the new microarrays technology to predict the tissue-of-origin (ToO) of CUP. This approach is eventually driven by the hypothesis that the knowledge of the putative primary could help customizing therapy and thereby improve clinical outcome.

Several methods for identifying CUP samples based on their gene expression profiles have been developed. Talantov D and coll. [48] and Varadhachary GR and coll. [49] have presented an RT-PCR based method that measures the expression of 10 signature genes. Ma XJ and coll. [50] proposed a similar method based on 92 genes, which resulted in an overall accuracy of $82 \%$ among 39 cancer types. Tothill RW and coll. [51] presented a support vector machine based method for classifying cancer types, and selected 79 genes for an RT-PCR test reaching a total accuracy of $89 \%$ but only among 13 cancer types. Rosenfeld $\mathrm{N}$ and coll. [52] applied a similar approach, but instead of measuring traditional gene expression, they looked at miRNA expression to classify CUP samples. For a majority of the samples, they achieved a $\sim 90 \%$ classification accuracy.

There are currently several commercial tests available with gene expression-based assays that classify tumors of unknown or uncertain origin: Pathwork [microarray for messenger RNA (mRNA)], Rosetta Genomics and Prometheus (RT-PCR for microRNA), and bioTheranostics (RT-PCR for mRNA). All tests claim prediction accuracies in known primary cancers between $80 \%$ and $90 \%$ [14]. However, each test has different specimen requirements and a wide range in their ability to identify cancer types/subtypes (15-54 types/subtypes). In general, a clinically viable test needs to be compatible with FFPE tissues with low numbers of tumor cells and to have the ability to discriminate large number of tumor types since metastatic cancers can arise from many cancer types and primary tumor sites. More recently Varadhachary GR and coll. [53] showed in a perspective study 
that $\mathrm{ToO}$ can be identified by using a microRNA-based assay in a high percentage (84\%) of metastatic cancers. Authors' conclusion suggested that microRNA assay may be most helpful in guiding management when IHC studies are unconclusive or provides a large differential diagnosis. Therefore, where applicable, those tests may be intended as complement to IHC to provide an multidisciplinary network for a most appropriate clinical management of CUP patients. Similar conclusions have been reached by Ferracin M and coll. [54] that demonstrated that FFPE samples can be used to reveal the ToO of metastatic cancer by using miRNA expression profile and suggested that this approach could provide useful indications for CUPs. It has also been documented that Pathwork test can be adequately performed on FFPE cell blocks from cytologic body fluid specimens material and can be used in the identification of $\mathrm{ToO}$ in case of metastases of unknown primary [55]. In all the reported works, authors argue that the availability of $\mathrm{ToO}$ holds promise for the increasing individualization of therapy for CUP patients [20]. Authors' ultimate goal is to provide a helpful framework where profiling and pathology are integrated in a cost and clinically effective algorithm with a positive impact on patient survival and quality of life. Molecular profiling for the identification of the $\mathrm{ToO}$ is a promising technique to improve the site of origin diagnosis in CUP patients, which could be exploited in the clinical practice. Interestingly, prospective clinical trials are ongoing to determine whether treatment based on molecular profiling can improve CUP patient outcomes. A major issue is to determine if CUP patients respond similarly to the corresponding subsets of patients with known primary when treated with site-specific therapy, based upon IHC profile and/ or molecular profiling assay. Besides, gene expression assays will be promising for diagnosis and hence therapy, in those cases displaying inconclusive IHC profile.

\section{Current therapeutic approach to CUPs}

Surgical management of metastases of unknown primary is generally related to limited/single disease. Nevertheless, a recent report demonstrated for the first time that surgery in case of multiple sites of spinal disease did not influence survival; whereas the presence of extraspinal disease had a negative impact [56]. However since CUP syndrome mainly presents with advanced disease systemic therapy is the most frequent approach.

The continuing development of new therapies targeted to the various cancer types makes mandatory the identification of the primary tumor and-as discussed abovemany efforts are now directed to integrate molecular based medicine and clinical practice to assign a primary as soon as possible after diagnosis of metastases of occult primary origin. However in case of CUP diagnosis, therapy regimes lack to be specific and, in the vast majority of cases, chemotherapy regimens include platinum, an alkylating agent which is effectively used for the management of patients with the most common solid tumors. In those settings, treatment may only help to control metastatic disease for a time and to improve patient symptoms. Overall clinical prognostic markers include: patient's age, gender, weight loss and performance status; histopatology and tumor burden, location and number of metastatic sites; as well as serum biomarkers [2]. In addition, the French CUP Group (GEFCAPI) developed a simple prognostic index for patients with CUP, in which favorable prognostic factors included a performance status $<2$ and normal serum LDH levels [57]. Several other algorithms are under investigation, with the aim to help clinicians involved in CUP patients care. Interestingly, the survival of CUP patients who are enrolled in clinical trials significantly higher (6-10 months) if compared to that of unselected CUP patients who are not enrolled in clinical trials (2-3 months) [58].

For adequate therapeutic guidance CUP entities should be categorized into favorable or unfavorable subsets [59]. In the recently published ESMO guidelines [1], it has been clearly stated that treatment has to be tailored on an individual basis according to the clinicalpathological subset of distinct prognosis in which the patient belongs. About 10-15\% of CUP patients of the favorable risk subsets should be treated similarly to patients with equivalent known primary tumors with metastatic dissemination. As discussed above, patients who belong to these subcategories have a better prognosis and undergo specific recommended treatments. Indeed in those cases, retrospective analyses have shown that patients'outcome displays no substantial differences from those with metastatic tumors of known primary. On the other hand, patients with poor-risk CUP have a dismal prognosis despite management with a variety of chemotherapeutic combinations in small clinical studies. Notably, no superior efficacy has been proven-till nowwith respect to any of the tested schedules incorporating platinum, taxanes or third generation compounds [60].

Carboplatin plus paclitaxel combination chemotherapy has been reported to be effective in patients with predominantly nodal/pleural metastases of unknown primary carcinoma and in women with peritoneal carcinomatosis but showed lower benefits in patients affected by liver, bone or multi-metastatic disease [61]. Similar results were obtained by Park YH and coll. in 2004 [62] whose study evaluated the efficacy and toxicity of combined paclitaxel and cisplatin chemotherapy in a subset of CUP patients, mainly affected by adenocarcinomas. In this phase II study the median survival was 11 months whereas the median time to progression was 4 months. 
In 2007 Pentheroudakis G and coll. published a study demonstrating that combination docetaxel carboplatin is a safe and effective palliative option for CUP patients [63]. Also combinatorial triplets with gemcitabine or etoposide, carboplatin, and paclitaxel seem to be tolerable treatment for CUP patients [64,65]. A recently closed phase II trial evaluated the efficacy and toxicity of the combination of paclitaxel, carboplatin, bevacizumab, and erlotinib in the first-line treatment of CUP patients [66]. All the enrolled patients received the four drugs and treatment cycles were repeated every 21 days. When carboplatin/paclitaxel were discontinued, bevacizumab/erlotinib were continued until tumor progression. This empiric drugs combination allowed a median progression-free survival time of 8 months, with $38 \%$ of patients being progression free at 1 year. The median survival time and 2-year overall survival rates were 12.6 months and $27 \%$, respectively; toxicity profile was well tolerated. Randomized prospective trials proving that any form of chemotherapy improves the survival of CUP patients with disseminated adeno-or undifferentiated carcinoma over best supportive care alone are still lacking. Nevertheless platinum-based combination schedules represent the first line approach to CUP treatment and because of the lower toxicity of carboplatin as compared to cisplatin, the favored regimen is carboplatin/paclitaxel. With this combination, response rates of $30-40 \%$ and a 2 -year survival rate of $20-25 \%$ can be achieved if administered as first-line therapy [67]. Few data are available about second-line chemotherapy in CUP patients who already received platinum-based first-line treatment. Although it remains unclear whether secondline chemotherapy might contribute to a survival benefit in patients with CUP, patients who show a favorable response to first-line chemotherapy appear to be likely to benefit from second-line chemotherapy [68]. Chemotherapy regimens evaluated include the combination of oxaliplatin and capecitabine which has been found to have activity as salvage treatment for patients with CUP, mainly in those feature a so called 'colon cancer profileCUP' [69].

Radiotherapy is a conventional therapeutic approach in case of cervical lymphnodes metastases of unknown origin, not only for unresectable disease but for a comprehensive treatment of the whole neck. Indeed neck dissection is not always necessary; for instance, it is not necessary for N1 disease [70]. Intensity modulated radiation therapy (IMRT) can produce excellent outcomes without relevant long term complications [71]. Definitive IMRT to 50-56 Gy followed by neck dissection seems to result in excellent nodal control and overall and diseasefree survival, with acceptable toxicity for patients with localized non-bulky disease without extracapsular spread, T0N1 or non-bulky T0N2a stages [72]. Relapse occurred infrequently in patients treated with excisional biopsies and postoperative radiotherapy. These results appear consistent with those expected for patients with advanced neck disease and a known primary site [73]. In summary results from chemotherapy and radiotherapy on CUP patients do not exclude them from studies aiming to improve their outcomes. Indeed, in the last decade it has been largely shown that cancers belonging to the same tissue/organ do not respond to treatment in the same way, and response to treatment lies inside their genome: presence or absence of specific genetic lesions (either mutations or amplifications) can really predict responses to therapy. Ultimately a mutational profile, rather than prediction of $\mathrm{ToO}$, could be useful to treat patients with targeted therapies. Steady collaboration and fluid communication between oncologists, pathologists and molecular biologists is a clear priority for the correct interpretation of tests and the personalized approach required by each individual CUP case. Work in multidisciplinary teams will result in significant changes in the diagnosis and treatment of these patients

\section{CUP: unknown primary or unknown biology?}

Metastatic spread is generally considered the final step of tumor progression and it clinically sets up the worse level of the cancer staging system. According to this model, the early cancer diagnosis is the one able to detect a single localized tumor mass which is still susceptible of surgical exeresis. However, as discussed above, in 3-5\% of all human cancers distant dissemination arises at an early stage of tumor progression, so that unexpected metastatic phenotype can overcome on the primary lesion's growth. In some of those cases the putative primary can be detected by routine IHC stains or at least through gene expression profiling. On the contrary, in some instances morphology, imaging and molecular predictive assays are 'noncontributory': only these samples could be correctly defined as CUPs.

Thus, there are at least two different hypotheses which can be involved in CUP biology: i) the first suggests that CUPs are heterogeneous group of site-specific tumors which share the properties of the small primary from which derive; ii) the second regards to CUP as to a distinct entity with a specific genetic asset. It is clearly evident that the biological and genetic enigma that could be related to CUPs is enclosed in the molecular mechanisms that speed up distant metastatization so that to confer to the primary lesion a status comparable to dormancy. In other words, it is conceivable that CUPs are a distinct biological entity involving specific genetic and phenotypic alterations, although at the present there are no known and validate molecular features to clearly distinguish these cancers. This observation is 
further supported by a recent epidemiological analysis performed on a CUP cohort from the Swedish Family Cancer Database. This study showed that CUPs cluster with families of kidney, lung, and colorectal cancers and suggested a marked genetic basis in the onset of the syndrome [74].

A wide variety of chromosomal abnormalities have been described in CUPs: aberration of chromosome 1, 6 , 7 and 11 are the most frequently reported [75]. Aneuploidy has been seen in $70 \%$ of adenocarcinomas of unknown primary: no relationship has been found with the pattern of metastatic spread or the overall survival [76]. Overall data on chromosomal abnormalities can be considered similar to those reported in case of cancers with known primary.

With respect to the oncogenic molecular asset of CUP, several studies have evaluated the expression and the mutational status of both oncogenes and tumor suppressor genes. Unexpectedly-although few studies are available-lesions of the key players know to drive the vast majority of human cancer cannot be documented in CUPs. Expression of c-myc, KRAS, HER2 has been studied by IHC in a series of 26 CUP cases and was present in less than one third of samples [77]. Nevertheless this observation does not allow a clear classification of CUPs. Indeed KRAS alterations, for example, are present in just about $30 \%$ of cases of human cancer as a whole and therefore, no significant differences seem to exist between the latter and CUP in this perspective.

Interestingly immunohistochemistry studies demonstrated that EGFR is frequently expressed in CUPs, whereas C-KIT and HER2/neu are infrequently activated. Notably no significant association has been established between EGFR expression level and patients prognosis [78].

The EGFR oncogene seems to be infrequently mutated (1\% data by Sanger Institute Catalogue of Somatic Mutations in Cancer-COSMIC-http://www.sanger.ac. uk/cosmic) in CUP whereas the intron 1 cytosine-adenosine (CA) repeat has been reported [79] to be increased in absence of correlation with patients survival and prognosis. Previous observations [80] also demonstrate that p53 mutations rarely occur in CUPs, thus suggesting a minor role of the protein in CUP onset.

Precocious undifferentiated neoplastic spread is the hallmark of CUP and this fact represents a strong rationale to investigate molecular pathways involved in metastatic process. Very recently Koo JS et al. [81] showed that hypoxia-related proteins are expressed in nodal squamous cell metastases of head and neck of unknown primary. The Glut-1, HIF1 $\alpha$, and COX2 expression level seems to be related to a worse patient prognosis.

Metastasis follows the inappropriate activation of a genetic program termed 'invasive growth' (or epithelial- mesenchymal transition), which is a physiological process that occurs during embryonic development and postnatal organ regeneration [82]. Burgeoning evidence indicates that invasive growth is executed by stem and progenitor cells, and is usurped by cancer stem cells. The MET proto-oncogene, which is expressed in both stem and cancer cells, is a key regulator of invasive growth [83]. MET encodes the tyrosine-kinase receptor for "Scatter Factor", a sensor of adverse microenvironmental conditions (such as hypoxia [84] and ionizing radiations [85]) and drives cell invasion and metastasis through the transcriptional activation of the 'invasive growth signature', a genetic program including cell scattering, invasion, protection from apoptosis and angiogenesis [86]. In human cancers, MET activation generally occurs as a late event, mainly consequent to receptor overexpression or gene amplification. Somatic point mutations are rarely found, accounting for no more than 3-4\% of unselected primary cancers (data from by Sanger Institute Catalogue of Somatic Mutations in Cancer-COSMIC-http://www. sanger.ac.uk/cosmic).

Several strategies to block the activation of MET are under development, such as the use of tyrosine kinase inhibitors or monoclonal antibodies and some of these compounds have already been used in clinical trials [87].

We have recently demonstrated [88], by a screening of about 50 CUP patients for occurrence of MET somatic mutations, an extremely high MET mutational incidence (about $15 \%$, vs. the $1-3 \%$ of the general cancer population), in the absence of high mutational background. Nucleotide changes found clustered either in the kinase domain or in the extracellular semaphorin domain. Mutated receptors were functional and sustained the transformed phenotype, suggesting that MET activating mutations are genetic markers associated with the CUP syndrome. Therefore, MET mutation may as well reflect either differentiation grade and/or organ of origin. In this respect a preferential expression of MET in cancer stem cells has been postulated [83].

\section{Conclusions}

Metastases are defined as macroscopic lesions which develop far, through blood or lymphatic vessels from the primary tumor: they are generally resistant to therapy and eventually lead patients to death. The molecular and cellular mechanisms which drive the metastatic spread are the topic of constant debate and scientific research due to the potential implications for cancer patients' prognosis. The process of metastases might begin before the growth of the primary mass. Recent evidence suggests that tumor cells might start conditioning for distant tissues colonization through the establishment of a so called 'pro-metastatic' niche [89]. Early metastatic dissemination is reflected in the clinical 
absence of symptoms (dormancy) of the primary tumor. CUPs identify a very aggressive pathology which-at the present- is still lacking for appropriate therapies. Indeed these tragic cases may be described as not only of unknown origin with respect to the organ site but also as of unknown pathogenesis. Despite many studies are focused on tracking their putative origin, the real enigma represented by CUPs is related to their own biological and genetic setting. Besides, growing evidence sustains that rationale for personalized targeted therapies is inside the tumors' genome rather than in their tissue of origin. Certainly this is true for all advanced cancers and not specifically for CUPs.

This ideal of personalized oncology has not been reached for most patients and the clinical reality at this time is that at least some CUP patients may be treated with more effective by recognizing their tissue of origin. Patients with advanced cancer whether the primary site is known or not, may eventually be treated based upon specific genomic abnormalities that are discovered in their cancer cells. This is already occurring in some instances. However, knowing the tissue of origin remains an immediate important factor in determining therapy for most patients with advanced cancer.

Nevertheless, further studies should be addressed to deeper investigate the molecular profile of CUPs. Preliminary results suggest a role for MET somatic mutations as driving force in CUP syndrome and put MET among the most promising therapeutic targets. Main address should be also focused on the potential role of the cancer stem cells compartment. Data should be collected to characterize the role played by undifferentiated cancer cells in tumor dissemination and their interaction with surrounding stroma to define molecular markers able to detect cancers displaying occult disseminative potential. This approach will lead to the creation of a new sensitive platform that might select an otherwise heterogeneous group of patients, such as that of patients presenting with metastatic cancers of unknown primary site of origin.

\footnotetext{
Abbreviations

CUP: Cancer of unknown primary origin; IHC: Immunohistochemistry; CT: Computed tomography; MRI: Magnetic resonance imaging; PET: Positron emission tomography; FDG: Fluorodeoxy-glucose; ToO: Tissue of origin; RTPCR: Reverse transcriptase pōlymerāse chain reaction; RNA: Ribonucleic acid FFPE: Formalin-fixed paraffin-embedded; CK: Cytokeratin; TTF: Thyroid transcription factor; ER: Estrogen receptor; CĀ125: Cancer antigen 125; VIM: Vimentin; PSA: Prostate specific antigen; CCP-CUP: Colon cancer profilecancer of unknown primary origin; IMRT: Intensity modulated radiation therapy; K-RAS: v-Ki-ras2 kirsten rat sarcoma viral oncogene homolog; EGFR Epidermal growth factor receptor; HIF: Hypoxia inducible factor; COX: Cyclooxygenase; GluT: Glucose transporter
}

\section{Acknowledgements}

GMS is a recipient of a fellowship (Assegno di Ricerca) by University of Turin and is supported by AIRC-Associazione Italiana Ricerca sul Cancro (Principal
Investigator Grant to PM Comoglio, $n^{\circ}$ 11852). PC is supported by Ricerca Sanitaria Finalizzata Regione Piemonte.

We thank Antonella Cignetto, Michela Bruno, and Daniela Gramaglia for secretarial help.

\section{Author details}

Department of Oncological Sciences, Institute for Cancer Research and Treatment (IRCC), 10060 Candiolo (Turin), Italy. ${ }^{2}$ Department of Molecular Medicine, - Section of Pneumology, Laboratory of Biochemistry \& Genetics; University and Fondazione IRCCS Policlinico San Matteo, 27100 Pavia-Italy. ${ }^{3}$ Department of Biomedical Sciences and Human Oncology, University of Turin, 10128 Turin, Italy.

\section{Authors' contributions}

GMS, RS and PC were involved in the conception of the manuscript; AC and MR contribute to collect and analyze bibliographic references; GMS, RS and PC structured and wrote the manuscript. All the authors approved the final version of the manuscript.

\section{Competing interests}

The authors declare that they have no competing interests.

Received: 17 October 2011 Accepted: 24 January 2012

Published: 24 January 2012

\section{References}

1. Fizazi K, Greco FA, Pavlidis N, Pentheroudakis G: On behalf of the ESMO guidelines working group. Cancers of unknown primary site: ESMO Clinical Practice Guidelines for diagnosis, treatment and follow-up. Ann Oncol 2011, 22(suppl 6):vi64-vi68.

2. Abbruzzese $J$, Abbruzzese MC, Hess KR, Raber MN, Lenzi R, Frost P: Unknown primary carcinoma: natural history and prognostic factors in 657 consecutive patients. J Clin Oncol 1994, 12(8):1272-1280.

3. Pavilidis N, Fizazi K: Carcinoma of unknown primary (CUP). Crit Rev Oncol Hematol 2009, 69:271-278.

4. van de Wouw AJ, Jansen RL, Speel EJ, Hillen HF: The unknown biology of the unknown primary tumors: a literature review. Annals of Oncology 2003, 14(2):191-96

5. Holmes FF, Fouts TL: Metastatic cancer of unknown primary site. Cancer 1970, 26(4):816-820

6. Briasoulis $\mathrm{E}$, Pavlidis N: Cancer of unknown primary origin. Oncologist 1997, 2(3):142-152.

7. Pavlidis N, Briasoulis E, Hainsworth J, Greco FA: Diagnostic and therapeutic management of cancer of an unknown primary. Eur J Cancer 2003, 39:1990-2005.

8. Shu X, Liu H, Ji J, Sundquist K, Försti A, Sundquist J, Hemminki K: Subsequent cancers in patients diagnosed with cancer of unknown primary (CUP): etiological insights? Ann Oncol 2011.

9. Hainsworth JD, Gereco FA: Treatment of patients with cancer of unknown primary site. N Engl J Med 1993, 329(4):257-263.

10. Mierke CT: Cancer cells regulate biomechanical properties of human microvascular endothelial cells. J Biol Chem 2011, 286:40025-40037.

11. Ecles SA, Welch DR: Metastases: recent discoveries and novel treatment strategies. Lancet 2007, 307(9574):1742-1757.

12. Marchesi F, Locatelli M, Solinas G, Erreni M, Allavena P, Mantovani A: Role of CX3CR1/CX3CL1 axis in primary and secondary involvement of the nervous system by cancer. J Neuroimmunol 2010, 224(1-2):39-44.

13. Rowe RG, Weiss SJ: Breaching the basement membrane: who, when and how? Trends Cell Biol 2008, 18(11):560-574

14. Greco FA, Oien K, Erlander M, Osborne R, Varadhachary G, Bridgewater J, Cohen $\mathrm{D}$, Wasan $\mathrm{H}$ : Cancer of unknown primary: progress in the search for improved and rapid diagnosis leading toward superior patient outcomes. Ann Oncol 2011.

15. Dennis JL, Hvidsten TR, Wit EC, Komorowski J, Bell AK, Downie I, Mooney J, Verbeke C, Bellamy C, Keith WN, Oien KA: Markers of adenocarcinoma characteristic of the site of origin: development of diagnostic algorithm. Clin Cancer Res 2005, 11(10):3766-3772.

16. Rossi G, Nannini N, Costantini M: Morphology and more specific immunohistochemical stains are fundamental prerequisites in detection of unknown primary cancer. J Clin Oncol 2009, 27(4):649-650. 
17. De Jong $D$, Horlings $H$, Wesseling J, van't Veer L: In reply to Rossi G et al. J Clin Oncol 2009, 27(4):651-652

18. Horlings HM, van Laar R, Kerst JM, Helgason HH, Wesseling J, van der Hoeven JJ, Warmoes MO, Floore A, Witteveen A, Lahti-Domenici J, Glas AM, Van't Veer $L$, de Jong D: Gene expression profiling to identify the histogenic origin of metastatic adenocarcinomas of unknown primary. J Clin Oncol 2008, 26(27):4435-4441.

19. Varadhachary GR, Raber MN, Matamoros A, Abbruzzese JL: Carcinoma of unknown primary with a colon-cancer profile-changing paradigm and emerging definitions. Lancet Oncol 2008, 9(6):596-10.

20. Greco FA, Hainsworth JD: Cancer of unknown primary. In Cancer: Principles and Practice of Oncology.. 9 edition. Edited by: DeVita TV, Hellman S, Rosenberg SA. Philadelphia: Wolters, Kluwer/Lippincott, Williams and Wilkins; 2011:2033-2051.

21. Pavlidis N: Forty years experience of treating cancer of unknown primary. Acta Oncol 2007, 46(5):592-601

22. Boellaard R, Doherty MJ, Weber WA, Mottaghy FM, Lonsdale MN, Stroobants SG, Oyen WJ, Kotzerke J, Hoekstra OS, Pruim J, Marsden PK, Tatsch K, Hoekstra CJ, Visser EP, Arends B, Verzijlbergen FJ, Zijlstra JM, Comans EF, Lammertsma AA, Paans AM, Willemsen AT, Beyer T, Bockisch A, Schaefer-Prokop C, Delbeke D, Baum RP, Chiti A, Krause BJ: FDG PET and PET/CT: EANM procedure guidelines for tumour PET imaging: version 1.0. Eur J Nucl Med Mol Imaging 2010, 37(1):181-200.

23. von Schulthess GK, Steinert HC, Hany TF: Integrated PET/CT: current applications and future directions. Radiology 2006, 238(2):405-422.

24. Kwee TC, Kwee RM: Combined FDG-PET/CT for the detection of unknown primary tumors: systematic review and metaanalysis. Eur Radiol 2009, 19(3):731-744.

25. Werner MK, Pfannenberg C, Öksüz MÖ: Nonspecific FDG uptake in the tongue mimicking the primary tumor in a patient with cancer of unknown primary. Clin Imaging 2011, 35(5):405-407.

26. Dandekar MR, Kannan S, Rangarajan V, Purandare NC, Chaukar DA, Deshmukh A, D'cruz AK: Utility of PET in unknown primary with cervical metastasis: a retrospective study. Indian J Cancer 2011, 48(2):181-186.

27. Tos $T$, Klyver $H$, Drzewiecki $K T$ : Extensive screening for primary tumor is redundant in melanoma of unknown primary. J Surg Oncol 2011.

28. Deron PB, Bonte KM, Vermeersch HF, Van de Wiele C: Lymph node metastasis of squamous cell carcinoma from an unknown primary in the upper and middle neck: impact of (18)f-fluorodeoxyglucose positron emission tomography/computed tomography. Cancer Biother Radiopharm 2011, 6(3):331-4

29. Rudmik L, Lau HY, Matthews TW, Bosch JD, Kloiber R, Molnar CP, Dort JC: Clinical utility of PET/CT in the evaluation of head and neck squamous cell carcinoma with an unknown primary: A prospective clinical trial. Head Neck 2011, 33(7):935-940.

30. Hu M, Zhao W, Zhang PL, Ju GF, Fu Z, Zhang GL, Kong L, Yang YQ, Ma YD, Yu JM: Clinical applications of 18 F-fluorodeoxyglucose positron emission tomography/computed tomography in carcinoma of unknown primary. Chin Med J (Engl) 2011, 124(7):1010-14.

31. Park JS, Yim JJ, Kang WJ, Chung JK, Yoo CG, Kim YW, Han SK, Shim YS, Lee SM: Detection of primary sites in unknown primary tumors using FDG-PET or FDG-PET/CT. BMC Res Notes 2011, 4:56.

32. Pak K, Kim SJ, Kim IJ, Nam HY, Kim BS, Kim K, Kim YK: Clinical implication of (18)F-FDG PET/CT in carcinoma of unknown primary. Neoplasma 2011, 58(2):135-139

33. Keller F, Psychogios $G$, Linke R, Lell M, Kuwert T, Iro H, Zenk J: Carcinoma of unknown primary in the head and neck: Comparison between positron emission tomography (PET) and PET/CT. Head Neck 2010.

34. Yabuki K, Tsukuda M, Horiuchi C, Taguchi T, Nishimura G: Role of 18 F-FDG PET in detecting primary site in the patient with primary unknown carcinoma. Eur Arch Otorhinolaryngol 2010, 267(11):1785-1792.

35. Salem S, Patel NH, Barwick T, Al-Nahhas A, Howard DJ, Zerizer I, Win Z: Occult squamous cell carcinoma of the uvula detected by F-18 FDG $\mathrm{PET} / \mathrm{CT}$ in a case of carcinoma of unknown primary in the head and neck. Clin Nucl Med 2010, 35(10):800-801.

36. Prasad V, Ambrosini V, Hommann M, Hoersch D, Fanti S, Baum RP: Detection of unknown primary neuroendocrine tumours (CUP-NET) using (68)Ga-DOTA-NOC receptor PET/CT. Eur J Nucl Med Mol Imaging 2010, 37(1):67-77.

37. Roh JL, Kim JS, Lee JH, Cho KJ, Choi SH, Nam SY, Kim SY: Utility of combined (18)F-fluorodeoxyglucose-positron emission tomography and computed tomography in patients with cervical metastases from unknown primary tumors. Oral Oncol 2009, 45(3):218-224.

38. Cianchetti M, Mancuso AA, Amdur RJ, Werning JW, Kirwan J, Morris CG, Mendenhall WM: Diagnostic evaluation of squamous cell carcinoma metastatic to cervical lymph nodes from an unknown head and neck primary site. Laryngoscope 2009, 119(12):2348-2354.

39. Padovani D, Aimoni C, Zucchetta P. Paluzzi A, Pastore A: 18-FDG PET in the diagnosis of laterocervical metastases from occult carcinoma. Eur Arch Otorhinolaryngol 2009, 266(2):267-271

40. Kaya AO, Coskun U, Unlu M, Akdemir UO, Ozdemir NY, Zengin N, Benekli M, Yildiz R, Yaman E, Ozturk B, Gumus M, Uner A, Yamac D, Ucgul E, Buyukberber S: Whole body 18 F-FDG PET/CT imaging in the detection of primary tumours in patients with a metastatic carcinoma of unknown origin. Asian Pac J Cancer Prev 2008, 9(4):683-636.

41. Hu M, Li MH, Kong L, Liu NB, Yang GR, Yu JM: (18)F-FDG PET-CT in detecting the primary tumor in patients with metastatic cancers of unknown primary origin. Zhonghua Zhong Liu Za Zhi 2008, 30(9):699-701.

42. Dong MJ, Zhao K, Lin XT, Zhao J, Ruan LX, Liu ZF: Role of fluorodeoxyglucose-PET versus fluorodeoxyglucose-PET/computed tomography in detection of unknown primary tumor: a meta-analysis of the literature. Nucl Med Commun 2008, 29(9):791-802.

43. Johansen J, Buus S, Loft A, Keiding S, Overgaard M, Hansen HS, Grau C, Bundgaard T, Kirkegaard J, Overgaard J: Prospective study of 18FDG-PET in the detection and management of patients with lymph node metastases to the neck from an unknown primary tumor. Results from the DAHANCA-13 study. Head Neck 2008, 30(4):471-478.

44. Nassenstein K, Veit-Haibach P, Stergar H, Gutzeit A, Freudenberg L, Kuehl H, Fischer M, Barkhausen J, Bockisch A, Antoch G: Cervical Lymph Node Metastases of Unknown Origin: Primary Tumor Detection with WholeBody Positron Emission Tomography/Computed Tomography. Acta Radiol 2007, 23:1-8.

45. Garin E, Prigent-Lejeune F, Lesimple T, Barge ML, Rousseau C, Devillers A, Bouriel C, Habiba MT, Bernard AM, Bridji B, Resche I: Impact of PET-FDG in the diagnosis and therapeutic care of patients presenting with metastases of unknown primary. Cancer Invest 2007, 25(4):232-239.

46. Paul SA, Stoeckli SJ, von Schulthess GK, Goerres GW: FDG PET and PET/CT for the detection of the primary tumour in patients with cervical nonsquamous cell carcinoma metastasis of an unknown primary. Eur Arch Otorhinolaryngol 2007, 264(2):189-195.

47. Ambrosini V, Nanni C, Rubello D, Moretti A, Battista G, Castellucci P, Farsad M, Rampin L, Fiorentini G, Franchi R, Canini R, Fanti S: 18 F-FDG $\mathrm{PET} / \mathrm{CT}$ in the assessment of carcinoma of unknown primary origin. Radiol Med 2006, 111(8):1146-1155.

48. Talantov D, Baden J, Jatkoe T, Hahn K, Yu J, Rajpurohit Y, Jiang Y, Choi C, Ross JS, Atkins D, Wang Y, Mazumder A: A quantitative reverse transcriptase-polymerase chain reaction assay to identify metastatic carcinoma tissue of origin. J Mol Diagn 2006, 8(3):320-329.

49. Varadhachary GR, Talantov D, Raber MN, Meng C, Hess KR, Jatkoe T, Lenzi R, Spigel DR, Wang Y, Greco FA, Abbruzzese JL, Hainsworth JD: Molecular profiling of carcinoma of unknown primary and correlation with clinical evaluation. J Clin Oncol 2008, 26(27):4442-4448.

50. Ma XJ, Patel R, Wang X, Salunga R, Murage J, Desai R, Tuggle JT, Wang W, Chu S, Stecker K, Raja R, Robin H, Moore M, Baunoch D, Sgroi D, Erlander M: Molecular classification of human cancers using a 92-gene real-time quantitative polymerase chain reaction assay. Arch Pathol Lab Med 2006, 130(4):465-473.

51. Tothill RW, Kowalczyk A, Rischin D, Bousioutas A, Haviv I, van Laar RK, Waring PM, Zalcberg J, Ward R, Biankin AV, Sutherland RL, Henshall SM, Fong K, Pollack JR, Bowtell DD, Holloway AJ: An expression-based site of origin diagnostic method designed for clinical application to cancer of unknown origin. Cancer Res 2005, 65(10):4031-4040.

52. Rosenfeld N, Aharonov R, Meiri E, Rosenwald S, Spector Y, Zepeniuk M, Benjamin $H$, Shabes N, Tabak S, Levy A, Lebanony D, Goren $Y$, Silberschein E, Targan N, Ben-Ari A, Gilad S, Sion-Vardy N, Tobar A, Feinmesser M, Kharenko O, Nativ O, Nass D, Perelman M, Yosepovich A, Shalmon B, Polak-Charcon S, Fridman E, Avniel A, Bentwich I, Bentwich Z, Cohen D, Chajut A, Barshack I: MicroRNAs accurately identify cancer tissue origin. Nat Biotechnol 2008, 26(4):462-469.

53. Varadhachary GR, Spector $Y$, Abbruzzese $J$, Rosenwald $S$, Wang $H$, Aharonov R, Carlson HR, Cohen D, Karanth S, Macinskas J, Lenzi R, Chajut A, Edmonston TB, Raber MN: Prospective gene signature study using 
microRNA to identify the tissue of origin in patients with carcinoma of unknown primary. Clin Cancer Res 2011, 17(12):4063-4070.

54. Ferracin M, Pedriali $M$, Veronese A, Zagatti B, Gafà R, Magri E, Lunardi M, Munerato G, Querzoli G, Maestri I, Ulazzi L, Nenci I, Croce CM, Lanza G, Querzoli P, Negrini M: MicroRNA profiling for the identification of cancers with unknown primary tissue-of-origin. J Pathol 2011, 225(1):43-53.

55. Stancel GA, Coffey D, Alvarez K, Halks-Miller M, Lal A, Mody D, Koen T, Fairley T, Monzon FA: Identification of tissue of origin in body fluid specimens using a gene expression microarray assay. Cancer Cytopathol 2011.

56. Aizenberg MR, Fox BD, Suki D, McCutcheon IE, Rao G, Rhines LD: Surgical management of unknown primary tumors metastatic to the spine. $J$ Neurosurg Spine 2011.

57. Culine S, Kramar A, Saghatchian M, Bugat R, Lesimple T, Lortholary A, Merrouche Y, Laplanche A, Fizazi K: French Study Group on Carcinomas of Unknown Primary Development and validation of a prognostic model to predict the length of survival in patients with carcinomas of an unknown primary site. J Clin Oncol 2002, 20(24):4679-4683.

58. van de Wouw AJ, Janssen-Heijnen ML, Coebergh JW, Hillen HF: Epidemiology of unknown primary tumours; incidence and population based survival of 1285 patients in Southeast Netherlands, 1984-1992. Eur J Cancer 2002, 38:409-413.

59. Massard C, Loriot Y, Fizazi K: Carcinomas of an unknown primary origindiagnosis and treatment. Nat Rev Clin Oncol 2011, 8(12):701-710.

60. Golfinopoulos V, Pentheroudakis G, Salanti G, Nearchou AD, loannidis JP, Pavlidis N: Comparative survival with diverse chemotherapy regimens for cancer of unknown primary site: multiple-treatments meta-analysis. Cancer Treat Rev 2009, 35:570-573.

61. Briasoulis E, Kalofonos H, Bafaloukos D, Samantas E, Fountzilas G, Xiros N, Skarlos D, Christodoulou C, Kosmidis P, Pavlidis N: Carboplatin plus paclitaxel in unknown primary carcinoma: a phase II Hellenic Cooperative Oncology Group Study. J Clin Oncol 2000, 18(17):3101-3107.

62. Park YH, Ryoo BY, Choi SJ, Yang SH, Kim HT: A phase II study of paclitaxel plus cisplatin chemotherapy in an unfavourable group of patients with cancer of unknown primary site. Jpn J Clin Oncol 2004, 34(11):681-685.

63. Pentheroudakis G, Briasoulis E, Kalofonos HP, Fountzilas G, Economopoulos T, Samelis G, Koutras A, Karina M, Xiros N, Samantas E, Bamias A, Pavlidis N, Hellenic Cooperative Oncology Group: Docetaxel and carboplatin combination chemotherapy as outpatient palliative therapy in carcinoma of unknown primary: a multicentre Hellenic Cooperative Oncology Group phase II study. Acta Oncol 2008, 47(6):1148-1155.

64. Greco FA, Burris HA, Litchy S, Barton JH, Bradof JE, Richards P, Scullin DC Jr, Erland JB, Morrissey LH, Hainsworth JD: Gemcitabine, carboplatin, and paclitaxel for patients with carcinoma of unknown primary site: a Minnie Pearl Cancer Research Network study. J Clin Oncol 2002, 20(6):1651-1656.

65. Hainsworth JD, Erland JB, Kalman LA, Schreeder MT, Greco FA: Carcinoma of unknown primary site: treatment with 1-hour paclitaxel, carboplatin, and extended-schedule etoposide. J Clin Oncol 1997, 15(6):2385-2393.

66. Hainsworth JD, Spigel DR, Thompson DS, Murphy PB, Lane CM, Waterhouse DM, Naot Y, Greco FA: Paclitaxel/carboplatin plus bevacizumab/erlotinib in the first-line treatment of patients with carcinoma of unknown primary site. Oncologist 2009, 14(12):1189-9.

67. Krämer A, Hübner G, Schneeweiss A, Folprecht G, Neben K: Carcinoma of Unknown Primary-an Orphan Disease? Breast Care (Basel) 2008, 3(3):164-170

68. Møller AK, Pedersen KD, Abildgaard J, Petersen BL, Daugaard G: Capecitabine and oxaliplatin as second-line treatment in patients with carcinoma of unknown primary site. Acta Oncol 2010, 49(4):431-435.

69. Hainsworth JD, Spigel DR, Burris HA, Shipley D, Farley C, Macias-Perez IM, Barton J, Greco FA: Oxaliplatin and capecitabine in the treatment of patients with recurrent or refractory carcinoma of unknown primary site: a phase 2 trial of the Sarah Cannon Oncology Research Consortium. Cancer 2010, 116(10):2448-2454.

70. Cerezo L, raboso E, Ballestreros Al: Unknown primary cancer of the head and neck: a multidisplinary approach. Clin Trans/ Oncol 2011, 13(2):88-97.

71. Frank SJ, Rosenthal DI, Petsuksiri J, Ang KK, Morrison WH, Weber RS, Glisson BS, Chao KS, Schwartz DL, Chronowski GM, El-Naggar AK, Garden AS: Intensity-modulated radiotherapy for cervical node squamous cell carcinoma metastases from unknown head-and-neck primary site: M. D. Anderson Cancer Center outcomes and patterns of failure. Int J Radiat Oncol Biol Phys 2010, 78(4):1005-1010.
72. Shoushtari A, Saylor D, Kerr KL, Sheng K, Thomas C, Jameson M, Reibel J, Shonka D, Levine P: Read P Outcomes of Patients with Head-and-Neck Cancer of Unknown Primary Origin Treated with Intensity-Modulated Radiotherapy. Int J Radiat Oncol Biol Phys 2011.

73. Colletier PJ, Garden AS, Morrison WH, Goepfert H, Geara F, Ang KK: Postoperative radiation for squamous cell carcinoma metastatic to cervical lymph nodes from an unknown primary site: outcomes and patterns of failure. Head Neck 1998, 20(8):674-681.

74. Hemminki K, Ji J, Sundquist J, Shu X: Familial risks in cancer of unknown primary: tracking the primary sites. J Clin Oncol 2011, 29(4):435-440.

75. Natoli C, Ramazzotti V, Nappi O, Giacomini P, Palmeri S, Salvatore M, Landriscina $M$, Zilli M, Natali $P G$, Tinari N, lacobelli S: Unknown primary tumors. Biochim Biophys Acta 2011, 1816(1):13-24.

76. Hedley DW, Leary JA, Kirsten F: Metastatic adenocarcinoma of unknown primary site: abnormalities of cellular DNA content and survival. Eur J Cancer Clin Oncol 1985, 21(2):185-189.

77. Pavlidis N, Briassoulis E, Bai M, Fountzilas G, Agnantis N: Overexpression of C-myc, Ras and C-erbB-2 oncoproteins in carcinoma of unknown primary origin. Anticancer Res 1995, 15(6B):2563-2567.

78. Massard C, Voigt JJ, Laplanche A, Culine S, Lortholary A, Bugat R, Theodore C, Priou F, Kaminsky MC, Lesimple T, Pivot X, Coudert B, Douillard JY, Merrouche Y, Fizazi K: Carcinoma of an unknown primary: are EGF receptor, Her-2/neu, and c-Kit tyrosine kinases potential targets for therapy? Br J Cancer 2007, 97(7):857-861.

79. Dova L, Pentheroudakis G, Georgiou I, Malamou-Mitsi V, Vartholomatos G, Fountzilas G, Kolaitis N, Kitsiou E, Pavlidis N: Global profiling of EGFR gene mutation, amplification, regulation and tissue protein expression in unknown primary carcinomas: to target or not to target? Clin Exp Metastasis 2007, 24(2):79-86.

80. Bar-Eli M, Abbruzzese JL, Lee-Jackson, Frost P: p53 gene mutation spectrum in human unknown primary tumors. Anticancer Res 1993, 13(5A):1619-1623.

81. Koo JS, Kim H: Hypoxia-related protein expression and its clinicopathologic implication in carcinoma of unknown primary. Tumour Biol 2011, 32(5):893-904.

82. Trusolino L, Comoglio PM: Scatter factor and semaphorin receptors: cell signalling for invasive growth. Nat Rev Cancer 2002, 2(4):289-300.

83. Boccaccio C, Comoglio PM: Invasive growth: a MET-driven genetic programme for cancer and stem cells. Nat Rev Cancer 2006, 6(8):637-645.

84. Pennacchietti S, Michieli P, Galluzzo M, Mazzone M, Giordano S, Comoglio PM: Hypoxia promotes invasive growth by transcriptional activation of the met protooncogene. Cancer Cell 2003, 3(4):347-361.

85. De Bacco F, Luraghi P, Medico E, Reato G, Girolami F, Perera T, Gabriele P, Comoglio PM, Boccaccio C: Induction of MET by ionizing radiation and its role in radioresistance and invasive growth of cancer. J Natl Cancer Inst 2011, 103(8):645-661

86. Trusolino L, Bertotti A, Comoglio PM: MET signalling: principles and functions in development, organ regeneration and cancer. Nat Rev Mol Cell Biol 2010, 11(12):834-848.

87. Stella GM, Benvenuti S, Comoglio PM: Targeting the MET oncogene in cancer and metastases. Expert Opin Investig Drugs 2010, 19(11):1381-1394.

88. Stella GM, Benvenuti S, Gramaglia D, Scarpa A, Tomezzoli A, Cassoni P, Senetta R, Venesio T, Pozzi E, Bardelli A, Comoglio PM: MET mutations in cancers of unknown primary origin (CUPs). Hum Mutat 2011, 32(1):44-50

89. Kaplan RN, Riba RD, Zacharoulis S, Bramley AH, Vincent L, Costa C, MacDonald DD, Jin DK, Shido K, Kerns SA, Zhu Z, Hicklin D, Wu Y, Port JL, Altorki N, Port ER, Ruggero D, Shmelkov SV, Jensen KK, Rafii S, Lyden D: VEGFR1-positive haematopoietic bone marrow progenitors initiate the pre-metastatic niche. Nature 2005, 438(7069):820-827.

doi:10.1186/1479-5876-10-12

Cite this article as: Stella et al.: Cancers of unknown primary origin: current perspectives and future therapeutic strategies. Journal of Translational Medicine 2012 10:12. 